\title{
AVALIAÇÃO PROGRESSIVA NA \\ E. E. M. DR. BRUNILO JACÓ, REDENÇÃO/CE \\ http://dx.doi.org/10.5902/2318133837651
}

\author{
Fernando Moura Mendes ${ }^{1}$ \\ Joana Elisa Röwer²
}

\begin{abstract}
Resumo
O objetivo deste trabalho foi analisar as percepções e transformações na implantação do modelo de avaliação progressiva na E. E. M Dr. Brunilo Jacó, do município de Redenção/CE. Buscou-se compreender a percepção de agentes escolares - professores, gestores e estudantes -, assim como observar, comparativamente, as taxas de aprovação, reprovação, transferência e evasão, antes e após a implantação desse modelo avaliativo. As principais referências estudadas foram José Carlos Libâneo, Tomaz Tadeu da Silva, Heloísa Lück, Cipriano Luckesi e Antoni Zabala. Os resultados indicaram que a implantação da avaliação progressiva na escola não teve como consequência direta um maior índice de aprovações, mas facilitou o aprendizado, conforme depoimentos dos professores e estudantes. Esses resultados demonstram que outros aspectos interferem no processo de ensino e aprendizagem, como o aumento do número de alunos por sala. Conclui-se que a gestão escolar precisa continuar repensando os processos de avaliação diante das dinâmicas educacionais.

Palavras-chave: avaliação progressiva; ensino médio; escola.
\end{abstract}

\section{PROGRESSIVE EVALUATION IN MIDDLE SCHOOL E. E. M. DR. BRUNILO JACÓ}

\section{Abstract}

This paper deals with school evaluation and aims to analyze perceptions and transformations in the implementation of the progressive evaluation model in a regular high school state school in the municipality of Redenção/CE. To understand this process, we sought to understand the perception of school agents - teachers, managers and students -, as well as to observe the approval, disapproval, transfer and avoidance rates comparatively before and after the implementation of this evaluation model. The main theoretical references in the area of education and curriculum were José Carlos Libâneo, Tomaz Tadeu da Silva, Heloísa Luck, Cipriano Luckesi and Antoni Zabala. The results indicated that the implementation of the progressive evaluation in the school did not have as a direct consequence a higher approval rate, but teachers and students feel that the model facilitates learning. These results lead to consider other aspects that interfere in teachinglearning as the increase in the number of students per room. It is concluded that, in view of the observed, school management must continue to rethink the processes of evaluation in the face of educational dynamics.

Key-words: progressive evaluation; high school; school.

\footnotetext{
${ }^{1}$ Universidade da Integração Internacional da Lusofonia Afro-Brasileira, Brasil. E-mail: fernandomouramendes20@live.com.

2 Universidade da Integração Internacional da Lusofonia Afro-Brasileira, Brasil. E-mail: joanarower@unilab.edu.br.

\begin{tabular}{|l|l|l|l|l|l|}
\hline Regae: Rev. Gest. Aval. Educ. & Santa Maria & v. 8 & n. 17 & Pub. contínua 2019 & p. 1-13
\end{tabular}
}




\section{Introdução}

A ideia para a realização desta pesquisa decorreu da experiência vivida nos estágios supervisionados I e II, do curso de licenciatura em Sociologia, na E.

E. M Dr. Brunilo Jacó, do município de Redenção/CE. Ao longo desse período deparamo-nos com uma inédita experiência sobre o modelo de avaliação progressiva, cuja inovação se tornou o motivo inicial para a análise de sua implantação. No campo teórico a temática deste trabalho, que se refere à avaliação da aprendizagem, não se distancia dos debates atuais. Aliás, temas como a gestão escolar e a avaliação têm sido alvo de um debate crucial no processo de melhoria da qualidade do ensino no país. Nessa ótica, partimos do pressuposto de que a eficiência da organização escolar assegura melhores condições para a eficácia da aprendizagem e dos processos avaliativos.

Dessa forma, propomo-nos a analisar os resultados do processo de avaliação progressiva da escola, por intermédio das múltiplas relações entre seus agentes, assim como pela compreensão dos seus reflexos objetivos nas avaliações e, subsequentemente, pelos seus efeitos progressivos e regressivos.

Por outro lado, buscamos provocar e despertar na comunidade acadêmica, sobretudo nos estagiários, professores e gestores, a importância de contínuas reavaliações das atividades escolares, considerando um conjunto de ações sobre as condições pedagógicas, metodológicas e dos processos avaliativos.

\section{Metodologia do trabalho}

Esta pesquisa envolveu três etapas. A primeira fase desenvolveu-se com caráter qualitativo. Segundo Gerhardt e Silveira (2009), a pesquisa qualitativa "não se preocupa com representatividade numérica, mas com o aprofundamento da compreensão de um grupo social, de uma organização" (p. 31). Nessa fase inicial foi estabelecido o diálogo com as referências bibliográficas que, segundo Gil (2008), fazem parte, sobretudo livros e artigos científicos, de modo a poder conhecer os diferentes conceitos sobre esse campo.

Em seguida, na segunda fase, foi realizado um trabalho de campo por intermédio da técnica de entrevista. De acordo com Gil (2008) essa técnica permite o aprofundamento da pesquisa de modo mais flexível, na busca por comprovação e esclarecimento de respostas. Dentre as muitas técnicas utilizadas no campo das Ciências Sociais, a entrevista é a mais viável e utilizada na coleta de dados, pois apresenta algumas vantagens que facilitam essa recolha.

Já a terceira fase contou com a realização de uma pesquisa documental. $\mathrm{Na}$ concepção de Gil (2008), esse tipo de trabalho não é tão diferente da pesquisa bibliográfica. A diferença reside na natureza das fontes e dos documentos que ainda não receberam tratamentos analíticos e comportam, neste caso concreto, documentos de arquivos. Foram efetuadas análises documentais dos resultados finais do ano letivo 2007/2008, antes da implantação da avaliação progressiva, e dos anos letivos 2014/2015 e 2017/2018, depois da implantação da avaliação progressiva. Nesse ponto, a pesquisa teve caráter quantitativo no tratamento dos dados recolhidos. 
Portanto, a partir desse encadeamento metodológico, foram analisados e comparados os dados dos alunos antes e depois da implantação da avaliação progressiva no referido estabelecimento escolar. Foram consideradas quatros categorias analíticas: números de reprovação; números de aprovação; números de transferência; e números de evasão escolar.

\section{A concepção histórica da administração escolar}

O percurso da organização institucional da escola foi confundido, ao longo dos tempos, com o processo de administração das empresas. Libâneo (2008) afirma que a concepção tradicional de administração escolar, denominada de concepção técnicoracional, assentava em zelar pelo processo de hierarquização burocrática e centralizada dos recursos da escola. Fazer bom uso dos recursos da escola e sua manutenção eram elementos essenciais dos mecanismos básicos da organização escolar.

Por outro lado, também era fundamental que houvesse condições adequadas à realização dos processos pedagógicos de qualidade (Ferreira, 2009). Sobre a concepção técnico-racional, Libâneo (2008) ainda escreve que "a escola é tomada como realidade objetiva e neutra, que deve funcionar racionalmente e, por isso, pode ser planejada, organizada e controlada de modo a alcançar melhores índices de eficácia e eficiência" ( $p$. 120).

$\mathrm{Na}$ Inglaterra o antigo sistema educacional tinha como preocupação central o fracasso escolar com ênfase empírica e estatística, sem levar em consideração a crítica sobre essas variáveis (Silva, 2015). Para Barroso (1996) a concepção científico-racional da antiga administração escolar assentava no princípio metodológico positivista. Barroso (1996), numa perspectiva da análise crítica sobre a autonomia da escola, entende que é fundamental tomar em conta a própria natureza de competências das entidades decisórias, as quais ele denominou de autonomia decretada e autonomia construída. Porém, a referida administração, para além de delimitar as funções dos agentes pedagógicos, ainda os relega ao segundo plano, nas manutenções das condições e dos recursos (Ferreira, 2009).

No entanto, com a emergência das perspectivas críticas ou sócio-críticas nos Estados Unidos e, em seguida, na Inglaterra, foi posta em xeque a eficiência do antigo modelo. Segundo Silva (2015), nos EUA, em meados da década de 1920, houve a criação das instituições especializadas no estudo sobre o currículo, que tinham como referência as perspectivas tradicionais. Enquanto isso, na Inglaterra, por volta da década de 1960, houve a emergência da nova Sociologia da Educação, que se insurgiu contra o currículo e a escola tradicional, pois mantinham uma educação centralizada, ou seja, com ênfase nos resultados escolares.

\section{Um pouco da avaliação escolar no Brasil}

Sander (1982 apud Ribeiro; Machado, 2007) afirma que, desde o período colonial, a tradição jurídica europeia é o fundamento da organização do ensino brasileiro. Ribeiro (2008) tornou-se um dos pioneiros no campo de estudos sobre a organização do sistema de ensino no Brasil, em especial com a publicação do ensaio em torno da teoria da 
administração escolar. O autor dividiu os processos da administração escolar em três fases distintas, mas, ao mesmo tempo, complementares à realização da escolarização: antes: planejamento, previsão e organização; durante: comando e assistência à execução; e depois: medição (Ribeiro; Machado, 2007, p. 17).

Posteriormente emergiram no Brasil, no final da década de 1970, pesquisas sobre as políticas educacionais. Segundo Gatti (1983), "tema até então ausente em trabalhos de análise institucional e organizacional" (p. 4). A partir desse momento pesquisadores da área da Educação, das Políticas Educacionais e do Currículo se opuseram ao sistema de administração escolar centralizado por intermédio dos trabalhos de dissertações como os de Arroyo (1979), Gonçalves (1980), Félix (1984), Kuenzer (1980) e Paro (1988). Portanto, essas pesquisas criticavam não só o modelo centralizado organizacional do ensino, mas também se preocupavam com os resultados do processo de ensino e aprendizagem, fruto desse modelo.

\section{Concepções sobre avaliação}

A avaliação no contexto escolar vem de uma construção tradicional enraizada em práticas sociais ainda presente hoje em dia nas instituições. A opinião do senso comum sobre a avaliação recai somente no resultado: "quando se fala de avaliação de forma prioritária ou mesmo exclusiva, nos resultados obtidos pelos alunos" (Zabala, 2010, p. 195). Ainda hoje predomina a concepção de que o principal objeto e objetivo das avaliações se referem à avaliação do grau de alcance do aluno em relação a determinados objetivos, os quais são preestabelecidos pelo conjunto de normas e normativas.

De acordo com as ideias de Lück (2009), a avaliação pode ser compreendida pelos seguintes modelos: um monitoramento e avaliação geral dos resultados e um processo de avaliação, designadamente a formativa e a somativa. A autora trata das dimensões da avaliação pela compreensão de um conjunto de ações organizacionais, de acompanhamento e de averiguação geral das ações realizadas, feita pela avaliação escolar, como no caso da implantação do modelo de avaliação denominado avaliação progressiva e seus resultados concretos sobre os alunos.

Para tanto, Luckesi (2000) criou duas categorias que, segundo ele, não se deve confundir com a diferença entre avaliação da aprendizagem e exame, como se estes fossem processos de natureza e funções distintas. Luckesi (2000) concebe a avaliação da aprendizagem escolar como um processo que estaria presente no cotidiano dos agentes escolares, mais especificamente nos atos e práticas educativos, comprometidos em elevar a qualidade do ensino por um processo proativo das dinâmicas inclusivas e construtivas. Para o autor a avaliação seria um vetor que processa qualidades e valores da educação para dentro do sistema de ensino: a avaliação é a capacidade de identificar os obstáculos e proporcionar condições necessárias e adequadas à qualidade do ensino e aprendizagem.

\section{Entrevista sobre o modelo de avaliação progressiva com os agentes escolares}

Foram dois os questionários elaborados para entender, a partir dos agentes escolares, os modelos de avaliação em vigor e as expectativas dos resultados. O primeiro questionário foi aplicado à direção e aos professores. O segundo destinou-se aos alunos. 
No primeiro caso as questões procuraram refletir sobre: como é que se avalia o desempenho dos alunos face ao modelo de avaliação progressiva? Outra questão foi: quais as vantagens e desvantagens de modelo da avaliação progressiva? Para o exdiretor e atual vice-diretor da escola

"o modelo em si ele foi pensado para atender e minimizar os problemas da época e, a questão... dá pouca margem do anterior modelo estadual não dava os alunos/as, ou seja, que não permitiria com que esses/as tivessem oportunidade de superar as dificuldades anteriores das avaliações com precisões. Ainda ele, [...] as escolas do ensino médio não só aqui no [...], acredito eu, de que deparem também com os mesmos problemas das ineficiências dos alunos oriundos do ensino fundamental com serias problemas $e$ isso vem sendo esforços contemplado na avaliação progressiva, que vai muito além a sentido proporcional das notas dos alunos, contudo, os problemas "extraescolar" dos alunos, ou seja, problemas estrutural familiar dos alunos desde os pais e encarregados de educação de modo que, a maioria são provenientes das estruturas familiares desestruturadas que, tornam $o$ processo do ensino $e$ aprendizagem ainda mais ineficiente." (ED)

O ex-coordenador pedagógico e atual diretor da escola destacou as vantagens e as lacunas do antigo modelo de avaliação, bem como a eficácia da avaliação progressiva:

"Avaliação progressiva em si tem permite com que os alunos revisam-se todas as matérias das avaliações anteriores e em detrimento disso caso o aluno obtivesse boas notas ira automaticamente recuperar negativas nas quais obtiveram bons resultados na avaliação progressiva e assim como na verificação global consequentemente". Outras vantagens do modelo com o acréscimo etapas das avaliativas que encurta espaços de avaliações, ou seja, por exemplo: se no antigo modelo de avaliação o aluno levava dois meses para ter avaliação ele passará a tê-la menos de um mês e meio evitando assim acumulo das matérias para eles." (DI)

Em relação à mesma questão, a professora Lopes $^{3}$ realçou a impressão que tem sobre os resultados produzidos pelo modelo ao afirmar que

"do momento da implantação deste modelo tive receio quanto a sua dinâmica face os problemas que existia. Agora, se for hoje, para trocar esse atual modelo de Avaliação Progressiva, talvez nós os professores nem quiséssemos mais, porque os alunos têm oportunidade e, é uma forma muito interessante. Caso o aluno não estiver bem numa determinada disciplina ele terá toda oportunidade de se recuperar. Agora, em relação a desvantagem do modelo em si, eu francamente não a vejo." (PL)

O professor Vital também falou sobre as vantagens e reconheceu o modelo dos resultados até então alcançados. Por outro lado, destacou aquilo que, segundo ele, constituiu um obstáculo para o modelo de avaliação progressiva:

${ }^{3}$ Nome fictício.

Regae: Rev. Gest. Aval. Educ. 
"É importante destacar de que, esses resultados concretos foram alcançados, portanto, graças a perfeição ou combinação do atual modelo com momentos atuais. Agora, por outro lado, os percalços a este modelo seria justamente a questão de superlotação dos alunos em salas de aulas. Imaginem uma sala de aula aproximadamente com um universo de 43 alunos! Para além de enorme esforço sobre os ombros dos professores, como também tornaria obstaculizam-te o esforço do educador, onde a maioria desses adolescentes com bases familiares desestruturadas, portanto, fica difícil para os professores/as dar apoio suficiente ao número elevado desses alunos." (PV)

Sobre o modelo de avaliação progressiva, a questão proposta para os alunos foi: quais as vantagens e desvantagens do modelo de avaliação progressiva? De modo especial, o questionário foi aplicado aos alunos integrantes do Fórum Permanente de Alunos, que corresponde ao órgão representativo dos alunos da escola, equivalente ao Grêmio Escolar. O representante do $3^{\circ}$ ano afirmou que "as vantagens do modelo de avaliação progressiva possibilitam-nos em caso de notas baixas nas primeiras avaliações a nos esforçarmos para recuperar as notas desperdiçadas, portanto, não vejo algo de desvantagem em relação ao modelo que obstaculizam o nosso desempenho".

Para a representante do $2^{\circ}$ ano, o modelo de avaliação progressiva incentiva os alunos a se esforçarem cada vez mais:

"As vantagens do modelo em relação ao que a gente estudava no ensino fundamental para mim. As vantagens desse modelo de Avaliação Progressiva são, tanto quando o aluno muito dedicado as disciplinas, sobretudo, quando aluno tem resultados pouco bons nas primeiras avaliações ele tem muita chance de se recuperar. Contudo, admito que, se não tivesse esse sistema de avaliação muitos de nós (alunos) estaríamos reprovados por conta das notas baixas. Ora, eu não encontro desvantagens, o que ás vezes alguns de nós considera de desvantagem que para mim não é, quando o próprio aluno nas primeiras avaliações obtiver notas boas e depois se abrandou ou deixou de se esforçar nas outras avaliações a consequente digressão acarreta automaticamente na planilha e redime o rendimento da média final do aluno." (R2)

O representante do $1^{\circ}$ ano destacou que "este modelo tem vantagens para nós, comparado com o modelo da escola fundamental. A experiência do modelo daqui nos dá possibilidade de nos esforçarmos cada vez mais para alcançar nossos objetivos" (R1). Porém, os dados apurados da pesquisa apresentam um quadro panorâmico menos exaltante com relação aos resultados finais dos alunos, sobretudo no caso dos alunos do 1a ano, onde se verifica um maior número de reprovações e de evasão escolar.

\section{Levantamento e análise dos dados: antes e depois da avaliação progressiva}

Para demostrar as possíveis mudanças a partir do uso da avaliação progressiva na escola, foi necessário realizar um comparativo das taxas, principalmente de aprovação e reprovação. 
Tabela 1 -

Resultado final do letivo 2007/2008.

\begin{tabular}{c|c|c|c|c}
\hline Aprovados & Reprovados & Transferências & $\begin{array}{c}\text { Deixou de } \\
\text { frequentar }\end{array}$ & Total \\
\hline 656 & 45 & 13 & 77 & 791 \\
\hline $83 \%$ & $6 \%$ & $1 \%$ & $10 \%$ & $100 \%$ \\
\hline
\end{tabular}

Fonte: dados da escola.

Conforme a tabela 1 foram aprovados 656 alunos, o que equivalem a $83 \%$ dos matriculados no ano letivo. Reprovaram 45 alunos, o que correspondem a $6 \%$, e os que deixaram de frequentar foram 77 alunos, o que perfaz 10\%. Os dados ainda demonstram 13 alunos transferidos, totalizando $1 \%$.

Outro aspecto importante é a análise dos dados dos resultados finais dos alunos por cada ano referente ao ano letivo 2007/2008. Com esses dados será possível situar melhor as mudanças antes e pós-implantação da avaliação progressiva na escola. Além disso, também será viável identificar os possíveis obstáculos e apontar novos desafios.

A escola pesquisada contava com oito salas de aula de $1^{\underline{a}}$ ano do ensino médio no referido ano letivo, totalizando 306 matriculados.

Tabela 2 -

Resultado final do ano letivo 2007/2008, referente ao 1aㅡ ano do ensino médio.

\begin{tabular}{c|c|c|c|c}
\hline Aprovados & Reprovados & Transferências & $\begin{array}{c}\text { Deixou de } \\
\text { frequentar }\end{array}$ & Total \\
\hline 253 & 27 & 1 & 28 & 309 \\
\hline $81,9 \%$ & $9 \%$ & $0,1 \%$ & $9 \%$ & $100 \%$ \\
\hline
\end{tabular}

Fonte: dados da escola.

De acordo com a tabela 2, foram aprovados 253 alunos, total que corresponde a $82 \%$. Por outro lado, foram reprovados 27 alunos, que equivalem a $9 \%$. Apenas um aluno foi transferido, e 28 deixaram de frequentar ou abandonaram. Este último dado diz respeito a $9 \%$.

O $2^{\circ}$ ano do ensino médio, no ano letivo 2007/2008, contava com sete turmas. Estas somavam 290 alunos.

Tabela 3 -

Resultado final do ano letivo 2007/2008, referente ao $2^{\circ}$ ano do ensino médio.

\begin{tabular}{c|c|c|c|c}
\hline Aprovados & Reprovados & Transferências & $\begin{array}{c}\text { Deixou de } \\
\text { frequentar }\end{array}$ & Total \\
\hline 239 & 14 & 7 & 30 & 290 \\
\hline $82 \%$ & $5 \%$ & $3 \%$ & $10 \%$ & $100 \%$ \\
\hline
\end{tabular}

Fonte: dados da escola.

Foram aprovados 239 alunos, que representam 82\%. Em contrapartida, 14 alunos reprovaram, dado que corresponde a 5\%. Foram transferidos 7 alunos, que constituem $3 \%$, e 30 deixaram de frequentar ou desistiram, totalizando $10 \%$. 
No ano letivo 2007/2008 a escola contava com seis turmas do $3^{\circ}$ ano, com 192 alunos matriculados. Destes, 164 foram aprovados, quantidade que corresponde a $85 \%$ dos alunos. Quatro alunos reprovaram, ou seja, 2\%, enquanto que 5 foram transferidos. Ademais, 19 alunos deixaram de frequentar.

Tabela 4 -

Resultado final do ano letivo 2007/2008, referente ao $3^{\circ}$ ano do ensino médio.

\begin{tabular}{c|c|c|c|c}
\hline Aprovados & Reprovados & Transferências & $\begin{array}{c}\text { Deixou de } \\
\text { frequentar }\end{array}$ & Total \\
\hline 164 & 4 & 5 & 19 & 192 \\
\hline $85 \%$ & $2 \%$ & $3 \%$ & $10 \%$ & $100 \%$ \\
\hline
\end{tabular}

Fonte: dados da escola.

Considerando-se as tabelas apresentadas anteriormente, referentes ao ano letivo 2007/2008, é possível considerar dois pontos: um deles é o destaque para números de aprovação e o outro refere-se ao elevado número da evasão, sendo este superior ao das reprovações. Dessa forma, passa-se a visualizar as diferenças pós-implantação da avaliação progressiva com a utilização dos dados de 2014/2015 e 2017/2018.

Tabela 5 -

Resultado final do letivo 2014/2015.

\begin{tabular}{c|c|c|c|c}
\hline Aprovados & Reprovados & Transferências & $\begin{array}{c}\text { Deixou de } \\
\text { frequentar }\end{array}$ & Total \\
\hline 499 & 88 & 24 & 13 & 624 \\
\hline $80 \%$ & $14 \%$ & $4 \%$ & $2 \%$ & $100 \%$ \\
\hline
\end{tabular}

Fonte: dados da escola.

Diante dos resultados finais, a partir dos dados coletados após três anos experimentais de avaliação progressiva, ou seja, de uma implantação sequencial entre três anos do ensino médio, que começou com as turmas do $1^{\circ}$ ano, depois $2^{\circ}$ e $3^{\circ}$ anos, os resultados finais desse ano letivo evidenciaram que houve um gradual crescimento positivo em torno dos resultados finais dos alunos.

Portanto, no ano letivo 2014/2015 destacam-se três categorias: a diminuição da evasão escolar, a reprovação e a transferência. Por outro lado, verifica-se uma diminuição relativa ao percentual de aprovados com relação ao ano letivo 2007/2008, antes da avaliação progressiva.

A escola contava com seis salas de aulas, ambas do $1^{\circ}$ ano, com 225 alunos matriculados, dos quais 177 foram aprovados, 31 alunos reprovaram, 12 foram transferidos e 5 deixaram de frequentar. 
Tabela 6 -

Resultado final do ano letivo 2014/2015, referente ao $1^{\circ}$ ano do ensino médio.

\begin{tabular}{c|c|c|c|c}
\hline Aprovados & Reprovados & Transferências & $\begin{array}{c}\text { Deixou de } \\
\text { frequentar }\end{array}$ & Total \\
\hline 177 & 31 & 12 & 5 & 225 \\
\hline $79 \%$ & $14 \%$ & $5 \%$ & $2 \%$ & $100 \%$ \\
\hline
\end{tabular}

Fonte: dados da escola.

Em relação ao $2^{\circ}$ ano do ensino médio, no ano letivo 2014/2015, contava com 254 matriculados. Destes, 215 foram aprovados 24 reprovaram, 9 foram transferidos e 6 alunos deixaram de frequentar.

Tabela 7 -

Resultado final do ano letivo $2014 / 2015$, referente ao $2^{\text {a }}$ ano do ensino médio.

\begin{tabular}{c|c|c|c|c}
\hline Aprovados & Reprovados & Transferências & $\begin{array}{c}\text { Deixou de } \\
\text { frequentar }\end{array}$ & Total \\
\hline 215 & 24 & 9 & 6 & 254 \\
\hline $85 \%$ & $9 \%$ & $4 \%$ & $2 \%$ & $100 \%$ \\
\hline
\end{tabular}

Fonte: dados da escola.

A referida escola, no $3^{\circ}$ ano, do ano letivo $2014 / 2015$, contava com oito turmas do $3^{\circ}$ ano, totalizando 145 alunos matriculados.

Tabela 8 -

Resultado final do ano letivo 2014/2015, referente ao 3ํano do ensino médio.

\begin{tabular}{c|c|c|c|c}
\hline Aprovados & Reprovados & Transferências & $\begin{array}{c}\text { Deixou de } \\
\text { frequentar }\end{array}$ & Total \\
\hline 107 & 33 & 3 & 2 & 145 \\
\hline $74 \%$ & $23 \%$ & $2 \%$ & $1 \%$ & $100 \%$ \\
\hline
\end{tabular}

Fonte: dados da escola.

No ano letivo 2017/2018, a escola contava com 18 turmas, subdivididas entre alunos de $1^{\circ}, 2^{\circ}$ e $3^{\circ}$ ano, totalizando 649 alunos.

Tabela 9 - Resultado final do ano letivo 2017/2018 referente ao ensino médio.

\begin{tabular}{c|c|c|c|c}
\hline Aprovados & Reprovados & Transferências & $\begin{array}{c}\text { Deixou de } \\
\text { frequentar }\end{array}$ & Total \\
\hline 460 & 116 & 20 & 53 & 649 \\
\hline $71 \%$ & $18 \%$ & $3 \%$ & $8 \%$ & $100 \%$ \\
\hline
\end{tabular}

Fonte: dados da escola.

Tal como consta na tabela 9, no ano letivo 2017/2018, foram aprovados 460 alunos, valor que corresponde a $71 \%$. Os reprovados somam 116, isto é, $18 \%$. Vinte alunos foram transferidos, ou seja, $3 \%$; e, os que deixaram de frequentar foram 53 , correspondendo a $8 \%$. 
Tabela 10 -

Resultado final do ano letivo 2014/2015, referente ao 3ํano do ensino médio.

\begin{tabular}{c|c|c|c|c}
\hline Aprovados & Reprovados & Transferências & $\begin{array}{c}\text { Deixou de } \\
\text { frequentar }\end{array}$ & Total \\
\hline 460 & 116 & 20 & 53 & \\
\hline $71 \%$ & $18 \%$ & $3 \%$ & $8 \%$ & $100 \%$ \\
\hline
\end{tabular}

Fonte: dados da escola.

No ano letivo 2014/2015, a escola contava com cinco salas de aula de $1^{\circ}$ ano, com 261 alunos matriculados.

Tabela 11 -

Resultado final do ano letivo 2017/2018, referente ao $1^{\circ}$ ano do ensino médio.

\begin{tabular}{c|c|c|c|c}
\hline Aprovados & Reprovados & Transferências & $\begin{array}{c}\text { Deixou de } \\
\text { frequentar }\end{array}$ & Total \\
\hline 153 & 64 & 12 & 32 & 261 \\
\hline $59 \%$ & $24 \%$ & $5 \%$ & $12 \%$ & $100 \%$ \\
\hline
\end{tabular}

Fonte: dados da escola.

Segundo os dados do $1^{\circ}$ ano do ano 2017/2018, foram aprovados 153 alunos, o que representa 59\%. Em contrapartida, 64 reprovaram, dado que corresponde a $24 \%$. Além disso, 12 alunos foram transferidos, ou seja, $5 \%$, e 32 alunos deixaram de frequentar ou desistiram, correspondendo a $12 \%$.

Tabela 12 -

Resultado final do ano letivo 2017/2018, referente ao $1^{\circ}$ ano do ensino médio.

\begin{tabular}{c|c|c|c|c}
\hline Aprovados & Reprovados & Transferências & $\begin{array}{c}\text { Deixou de } \\
\text { frequentar }\end{array}$ & Total \\
\hline 153 & 64 & 12 & 32 & 261 \\
\hline $59 \%$ & $24 \%$ & $5 \%$ & $12 \%$ & $100 \%$ \\
\hline
\end{tabular}

Fonte: dados da escola.

Em relação ao $2^{\underline{a}}$ ano, a escola contou com seis turmas, totalizando 217 alunos matriculados.

Tabela 13 -

Resultado final do ano letivo 2017/2018, referente ao $2^{\circ}$ ano do ensino médio.

\begin{tabular}{c|c|c|c|c}
\hline Aprovados & Reprovados & Transferências & $\begin{array}{c}\text { Deixou de } \\
\text { frequentar }\end{array}$ & Total \\
\hline 175 & 18 & 6 & 18 & 217 \\
\hline $81 \%$ & $8 \%$ & $3 \%$ & $8 \%$ & $100 \%$ \\
\hline
\end{tabular}

Fonte: dados da escola. 
Do total de alunos matriculados no $2^{0}$ ano do ano letivo 2017/2018, 175 foram aprovados, o que corresponde a $81 \%$. Não obstante, 18 foram reprovados, ou seja, $8 \%$. Ademais, seis alunos foram transferidos, quantidade que corresponde $3 \%$, e 18 alunos deixaram de frequentar ou desistiram, estes correspondem a $8 \%$.

Quanto ao 3ำ ano, a escola contou com cinco turmas, totalizando 171 matriculados.

Tabela 14 -

Resultado final do ano letivo 2017/2018, referente ao $3^{\circ}$ ano do ensino médio.

\begin{tabular}{c|c|c|c|c}
\hline Aprovados & Reprovados & Transferências & $\begin{array}{c}\text { Deixou de } \\
\text { frequentar }\end{array}$ & Total \\
\hline 124 & 34 & 2 & 11 & 171 \\
\hline $73 \%$ & $20 \%$ & $1 \%$ & $6 \%$ & $100 \%$ \\
\hline
\end{tabular}

Fonte: Dados da escola.

Conforme a tabela 14, no $3^{\circ}$ ano do ano letivo 2017/2018, 124 alunos foram aprovados, o que equivale a $73 \%$. Desta vez 32 alunos foram reprovados, ou seja, $20 \%$. Por outro lado, apenas dois alunos foram transferidos, ou seja, $1 \%$. Já os que deixaram de frequentar foram 11 , o que representa $6 \%$.

Tabela 15 -

Resultado de todos os anos letivos.

\begin{tabular}{c|c|c|c}
\hline Situação/ano & $2007 / 2008$ & $2014 / 2015$ & $2017 / 2018$ \\
\hline Aprovados & $83 \%$ & $80 \%$ & $71 \%$ \\
\hline Reprovados & $6 \%$ & $14 \%$ & $18 \%$ \\
\hline Transferidos & $1 \%$ & $4 \%$ & $3 \%$ \\
\hline Evadidos & $10 \%$ & $2 \%$ & $8 \%$ \\
\hline
\end{tabular}

Fonte: dados da escola.

A partir dos dados apresentados, nota-se que houve um decréscimo em algumas categorias, sobretudo com relação às aprovações. Por conseguinte, também se observa a existência de um aumento relativo nas reprovações. Ademais, vale realçar que os maiores números, no que se refere aos reprovados, correspondem aos alunos dos primeiros anos do ensino médio. Para além disso, também se registou um ligeiro crescimento nos casos de transferências.

\section{Considerações finais}

O que se pretendeu com este trabalho foi fazer uma análise do sistema de avaliação progressiva implantada numa escola de ensino médio regular do município de Redenção, interior do Estado do Ceará. Para compreender esse processo, buscou-se pesquisar as percepções de agentes escolares - professores, gestores e estudantes -, assim como observar as taxas de aprovação, reprovação, transferência e evasão antes e após a implantação desse modelo avaliativo.

Cientes de que as taxas de aprovação, reprovação, transferência ou abandono não alteram ou decorrem exclusiva e isoladamente do novo sistema de avaliação, os resultados alcançados nesta pesquisa indiciam algumas possibilidades: 
a) a aglomeração dos alunos, com ênfase no $1^{\circ}$ ano, é um problema que constitui obstáculo pedagógico, sobretudo em função das deficiências que passam do ensino fundamental para o médio. Essas deficiências podem ser um dos aspectos responsáveis pelo maior índice de reprovação nesse ano;

b) as evidências do processo de modelo da avaliação progressiva apontam para a concordância dos agentes escolares em torno da implantação e permanência desse modelo. Contudo, em níveis percentuais, foram constatados aumento nos índices de reprovação e diminuição nos de aprovação;

c) a avaliação progressiva na escola constitui um tema desafiador na contraposição ao modelo tradicional de avaliação, pois não gera maior número de aprovações diretamente. Contudo, os estudantes sentem maior facilidade com ele;

d) é importante que o governo estadual reformule medidas que possam se adequar às situações locais, tais como: criar condições de acesso, de qualidade e de permanência, de modo que o modelo de avaliação progressiva continue a progredir e a proporcionar bons resultados. Esses bons resultados não se referem somente às questões pedagógicas, mas também ao aproveitamento dos conteúdos por parte dos educandos;

e) é necessário que haja um reajuste na quantidade de alunos por sala de aula, principalmente no caso do $1^{\text {a }}$ ano, pois é oportuno permitir que, efetivamente e com eficácia, o professor assuma o controle pedagógico dos seus educandos.

\section{Referências}

BARROSO, João. O estudo da autonomia da escola: da autonomia decretada à autonomia construída. In: BARROSO, João. O estudo da escola. Porto: Porto, 1996, p. 20-44.

CREDE. Projeto político-pedagógico da EEM Dr. Brunilo Jacó. Redenção: Crede, 2012.

FERREIRA, Juara R. Arthury de Almeida. Gestão escolar: desafios e possibilidades. Curitiba: Secretaria de Estado da Educação, 2009.

GATTI, Bernadete A. Pós-graduação e pesquisa em Educação no Brasil 1978-1981. Cadernos de Pesquisa, São Paulo, n. 44, p. 3-17, 1983.

GERHARDT, Tatiana Engel; SILVEIRA, Denise Tolfo (org.). Métodos de pesquisa. Porto Alegre: Ufrgs, 2009.

GIL, Antonio Carlos. Métodos e técnicas de pesquisa social. São Paulo: Atlas, 2008.

LIBÂNEO, José Carlos. Organização e gestão da escola teoria e pratica: Goiânia: Alternativa, 2008.

LÜCK, Heloísa. Dimensões de gestão escolar e suas competências. Curitiba: Positivo, 2009.

LUCKESI, Cipriano Carlos. O que é mesmo o ato de avaliar a aprendizagem? Porto Alegre: Artmed, 2000.

RIBEIRO, Djeissom Silva; MACHADO, Lourdes Marcelino. Teorias de administração escolar em Querino Ribeiro e Lourenço Filho: raízes e processos de constituição de modelos teóricos. RBPAE, v. 23, n. 1, p. 13-28, 2007.

RIBEIRO, Elisa Antônia. A perspectiva da entrevista na investigação qualitativa. Evidência: olhares e pesquisa em saberes educacionais, Araxá, n. 4, p. 129-148, 2008. 
SILVA, Tomaz Tadeu da. Documentos de identidade. Belo Horizonte: Autêntica, 2015. ZABALA, Antoni. A prática educativa: como ensinar. Porto Alegre: Artmed, 2010.

Fernando Moura Mendes é bacharel em Humanidades e licenciado em Sociologia pela Universidade da Integração Internacional da Lusofonia Afro-Brasileira.

Orcid: https://orcid.org/0000-0001-6635-4264.

Endereço: Rua São Francisco, 03 - 62790-000 - Redenção - CE - Brasil.

E-mail: fernandomouramendes20@live.com.

Joana Elisa Röwer é professora do curso de Sociologia do Instituto de Humanidades da Universidade da Integração Internacional da Lusofonia AfroBrasileira.

Orcid: https://orcid.org/0000-0002-5630-7509.

Endereço: Rua Dom Pedro II, 42 - 62790-000 - Redenção - CE - Brasil.

E-mail: joanarower@unilab.edu.br.

Recebido em 5 de abril de 2019.

Aceito em 27 de junho de 2019.

(c) (i) 